\title{
Research on the Impact of Human Capital Investment on Intergenerational Income Mobility
}

\author{
Yuxin $\mathrm{Yan}^{1}$ and Sijia Chu ${ }^{1, *}$ \\ ${ }^{1}$ School of Government, Beijing Normal University, Beijing, 100875, China \\ * Corresponding author. Email: 201821260026@mail.bnu.edu.cn
}

\begin{abstract}
The issue of intergenerational income flow is related to social equity and equal opportunities. In recent years, China's intergenerational income mobility has declined, showing a trend of class consolidation. As people's requirements for social justice are getting higher and higher, it is urgent to improve China's intergenerational income mobility. An essential mechanism of intergenerational income transmission is human capital represented by education. The improvement of education level will help individuals get rid of class constraints and realize intergenerational upward mobility. On the other hand, the imbalance of educational opportunities will strengthen class intergenerational transmission makes "the poor get poorer and the rich get richer." Based on the theoretical framework of human capital, this article analyzes the impact of family education investment and public education expenditure on intergenerational income mobility, and explores the existing problems and causes, and proposes relevant policy recommendations for improving public education expenditure on this basis.
\end{abstract}

Keywords: human capital; intergenerational income flow; public education investment; family education

investment

\section{INTRODUCTION}

Over the past 40 years of reform and opening up, China has made great achievements in economic and social development, and the income level of urban and rural residents has increased significantly. However, the income gap has always been large, and the problem of income inequality has continued to increase. According to data from the National Bureau of Statistics, China's Gini coefficient has remained above 0.46 in the past decade, and it has become one of the countries with high income inequality in the world. With the continuous deepening of China's market-oriented reforms, people's requirements for maintaining social fairness have gradually increased, and the issue of intergenerational income mobility has attracted widespread attention from all walks of life.

Intergenerational income mobility is a dynamic measurement of the social income distribution field, referring to the changes in the position of offspring relative to their parents in the income distribution [1]. The high intergenerational income flow shows that personal success mainly depends on one's own efforts rather than family background. It is an important manifestation of social justice [2]. Therefore, it will increase people's tolerance for income inequality and help alleviate social conflicts brought about by the widening income gap. At the same time, higher intergenerational income flows can also improve the efficiency of human capital allocation, thereby promoting high-quality economic development[3]. On the contrary, the low intergenerational income flow indicates that the income of the father generation and the income of the offspring are relatively high, which will dampen the enthusiasm of the people at the bottom, make the society unfair, cause inefficient allocation of human resources, and gradually solidify the social class. Gradually lose the continuous impetus for economic growth [4]. Therefore, the reduction of intergenerational income mobility is also an important incentive for a country to fall into the "middle income trap" [5].

In the research on the formation mechanism of income inequality, individual endowment and acquired education are undoubtedly the two most important factors. Many studies at home and abroad have proved that human capital investment is an important path of intergenerational transmission, and the economic and social status of the family obviously affects the accumulation of individual human capital. At this time, government public policies are needed to narrow the investment gap between rich and poor families. Therefore, as an important intermediate variable in the human capital transmission path of intergenerational income, public education plays an important role. This article will further clarify the mechanism of human capital investment on intergenerational income mobility, and propose relevant policy recommendations for the existing problems of public education in China. 


\section{THE MECHANISM OF HUMAN CAPITAL INVESTMENT ON INTERGENERATIONAL INCOME FLOW}

Human capital is referred to as "intangible capital". Compared with the concept of "material capital", human capital can bring individuals the knowledge and skills of lasting income through investment channels such as education, training, migration, and so on. Therefore, it is an important realization of intergenerational income flow, which is also a long-term and subtle transmission mechanism of intergenerational income flow. At present, as the most common and effective way, human capital investment represented by education has become the most important medium that affects intergenerational income flow, and has been generally recognized by the domestic academic community. It is mainly obtained through government investment in public education resources and family education resources, and has played an important role in the process of intergenerational transmission.

\subsection{Family Education Investment and Intergenerational Income Flow}

Becker \& Tomes (1979) first considered human capital theory into family economic behavior, and put forward a theoretical model of intergenerational income transmission, which believed that the income level of children is closely related to the human capital investment made by parents in the later period of their children. The accumulation of family human capital affects children's income in two ways. One is that the parent's human capital directly affects the child's human capital, which in turn affects the children's income; the other is that the parent's human capital affects the parent's income, and the parent's income will affect the child's human capital investment, which in turn affects the child's income.

First of all, parents with high levels of human capital are more aware of the importance of human capital to their children's employment, so they pay more attention to their children's education and are willing to invest in human capital. In addition, parents with higher education levels can help their children in their studies, to a certain extent, to solve their children's confusion in the process of studying, and have a subtle and subtle impact on their children.
On the contrary, some low-income families may not be able to give their children sufficient investment in education due to various subjective or objective factors. They may prefer their children to find employment as soon as possible, and are unwilling to continue investing in human capital after their children have completed compulsory education. Although parents with low levels of human capital can meet their children's educational needs as much as possible by reducing their own consumption, there is still insufficient investment.

Secondly, parents with higher levels of human capital earn higher income, and parental income is a necessary condition for human capital investment in their children, enabling their children to receive a better education and giving them a competitive advantage in the job market [6]. Some empirical research conclusions point out that the dependence of the income level of offspring on the income level of their parents gradually weakens with the increase of personal education. That is to say, the higher the education level of the offspring, the higher the corresponding intergenerational income mobility.

\subsection{Public Education Expenditure and Intergenerational Income Flow}

Domestic and foreign studies have shown that in addition to family human capital investment, government investment in public education resources is also another important factor affecting intergenerational income flow. In order to make up for the lack of family education investment, the state can use financial resources to invest in public education funds, thereby affecting children's access to education, improving educational inequality, and weakening the mediating effect of education in intergenerational mobility.

Fig. 1and 2 show the change trend of China's fiscal investment in education and its proportion of GDP since 2011. For a long time, China's public education funding has continued to rise. In 2019, it exceeded 4 trillion yuan for the first time. Since 2012, the proportion of GDP for the first time exceeded $4 \%$, and it has remained above $4 \%$ for the eighth consecutive year. Studies have shown that the government's massive financial investment in educational resources, equipment, and teachers will improve the overall quality of schools, have the most direct impact on the level of human capital of offspring, and effectively increase children's years of education. 


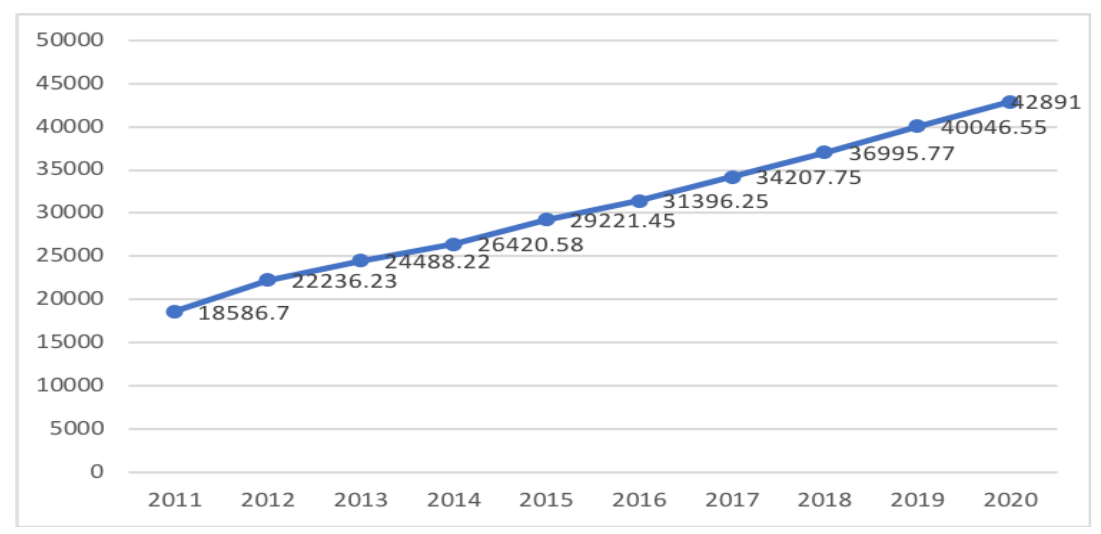

Figure 1. Changes in China's fiscal investment in education from 2011 to 2020. ${ }^{\mathrm{a}}$

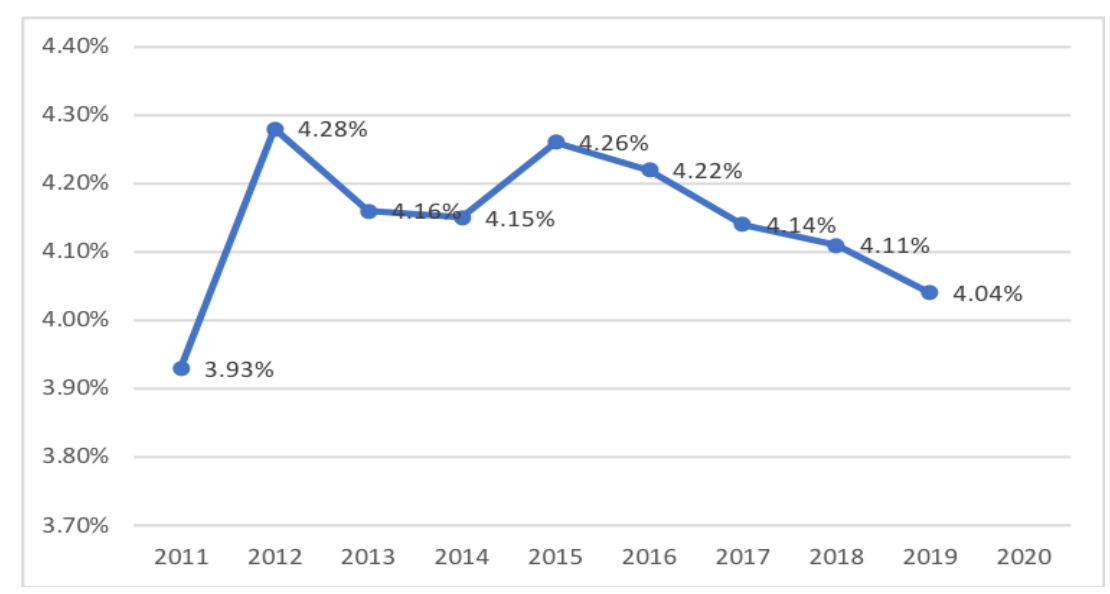

Figure 2. Changes in China's fiscal education expenditure as a proportion of GDP from 2011 to 2019. ${ }^{\text {a }}$

${ }^{a}$ The data comes from the "Statistical Announcement on the Implementation of National Education Funds" (2011-2020)

In addition, the importance of compulsory education is far greater than that of individuals' birth endowments and noncompulsory education. The government's massive investment in compulsory education plays a decisive role in alleviating income inequality and further enhancing intergenerational income flows. It makes citizens accept The opportunities for higher education are gradually increasing. As shown in Fig. 3, after China promulgated the Compulsory Education Law in 1986, the net enrollment rate of primary school-age children and junior high schools in China and the rate of enrollment of graduates have increased significantly. At the same time, after the expansion of university enrollment in 1999, higher education gradually entered the stage of popularization. As shown in Fig. 4, in 2019, the gross enrollment rate of higher education has exceeded $50 \%$, and the expansion effect is very obvious. 


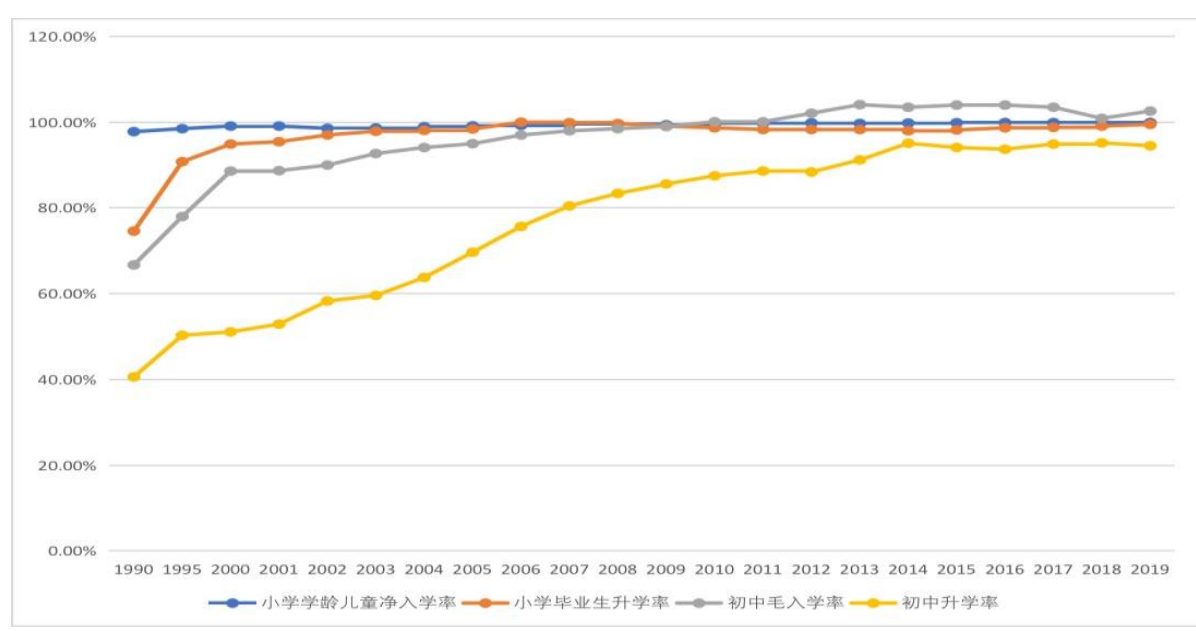

Figure 3. Changes in net enrollment of primary school-age children, enrollment of primary school graduates, junior high school gross enrollment and junior high school enrollment rates from 1990 to 2019 . ${ }^{\mathrm{b}}$

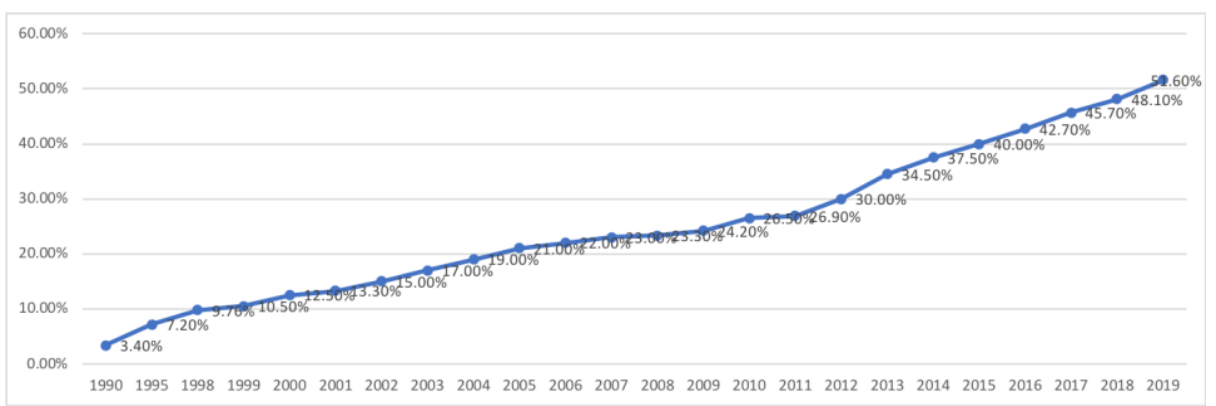

Figure 4. Changes in China's higher education gross enrollment rate from 1990 to $2019 .^{\mathrm{b}}$

bData comes from the China Education Statistics Yearbook (2007) and the "National Education Development Statistical Bulletin" (2011-2019)

In summary, education is not only the most important factor affecting intergenerational income flow, but also an important way to achieve intergenerational income flow. [7] Therefore, the effect of educational inequality plays an important role in the change of intergenerational income mobility, and is an important reason for China's current income gap expansion.

\section{PROBLEMS IN CHINA'S CURRENT PUBLIC EDUCATION EXPENDITURES}

Currently, China's overall intergenerational income mobility is relatively low. From the perspective of macro resource allocation, China's education resource expenditure has certain limitations, mainly manifested in the imbalance of allocation and irrational structure.

One is the imbalance in the allocation of public education expenditures between urban and rural areas and regions. This imbalance exists in almost every level of the education system, and is an important reason for the low mobility of China's overall intergenerational income. On the one hand, because urban resources are generally better than those in rural areas, and the household registration system limits the transfer of rural labor to a certain extent, rural households' income is generally lower than that in cities, which affects the family education investment of offspring. On the other hand, the imbalance in the distribution of public education makes it difficult for descendants of poor families at the bottom of society to receive education at all levels equally. This further affects the accumulation of human capital of offspring on the basis of low family education investment.

The second is the unreasonable structure of public education expenditure, which is mainly manifested in the unreasonable allocation of tertiary education under the established expenditure scale. On the one hand, the excessive tilt of public education expenditure to higher education is not conducive to the improvement of intergenerational income mobility. The hierarchical attribute of education requires that individuals must undergo the accumulation of elementary education to enter a higher level of education. Those who cannot receive better elementary education can hardly enter a higher level of education, so some offspring of low-income families have no opportunity to receive higher education, thus losing an important means of competing with offspring of high-income families. On the other hand, the excessive expansion of higher education has increased the number of university graduates and increased employment pressure, 
reducing the possibility of upward mobility of income from low-income families through higher education.

\section{CONCLUSION AND SUGGESTION}

This article analyzes the impact of human capital investment on intergenerational income flows and the current problems of public education expenditures in China. It is believed that human capital investment represented by education has a certain explanatory power for intergenerational income flows, which are mainly reflected in family education investment and public education.

Reasonable public education expenditure is an important measure to improve intergenerational income mobility and achieve equal opportunities. Therefore, in the face of problems such as imbalanced allocation of public education expenditures and irrational structure in China at this stage, government agencies should "prescribe the right medicine" to address the problems in public education, and promote the improvement of intergenerational income mobility as a whole. To this end, this article proposes the following countermeasures.

First, further expand the scale of public education expenditures. At present, China's public education expenditure level is only slightly higher than the average level of less developed countries, which is still far from the world average level. Therefore, the government should continue to increase investment in education and expand the scale of public education expenditures. On the one hand, we must further improve the public education policy to ensure that everyone has a fair opportunity to receive education. In particular, it is necessary to increase financial support for public education in poor areas, strengthen the improvement of teaching hardware facilities and the introduction of excellent teachers in poor areas, and continuously improve the teaching environment and teaching quality in poor areas; It is necessary to formulate targeted education subsidy policies that benefit the children of poor and disadvantaged families, such as improving the scholarship system, actively promoting the education level of the offspring of low-income groups, and enhancing their competitiveness in the labor market. On the other hand, it is necessary to improve the government performance appraisal system and incorporate factors such as the level of education development and education funding into the government performance appraisal system, so as to strengthen the importance of all levels of government on education investment and encourage the government to increase the scale of public education expenditure.

Second, further adjust the imbalance of public education expenditure. On the one hand, the central government should increase transfer payments for public education expenditures in economically underdeveloped areas, and expand the scale of central transfer payments to poor areas; Provincial governments should coordinate fiscal transfer payments to lower-level governments to gradually balance the distribution of educational resources in the province, and narrow the gap in the province; at the same time, gradually improve the intergovernmental transfer payment system to achieve counterpart assistance between governments, such as encouraging counterpart assistance between schools in economically developed and underdeveloped areas, sharing high-quality educational resources, promoting educational development, and achieving the goal of rational allocation of educational resources. On the other hand, it is necessary to promote the fairness of basic education between regions and between urban and rural areas. Educational financial investment should be oriented towards underdeveloped areas in the central and western regions and rural areas. The treatment of teachers in these areas should be improved to avoid brain drain, and a series of policies should be adopted to encourage the return of talents.

Third, further optimize the structure of public education expenditures. The distribution ratio of public education expenditure among all levels of education directly determines the efficiency of the use of public education expenditure. The government should continue to expand the distribution ratio of basic education in public education expenditures and adjust higher education funding on the basis of improving education investment legislation. Higher education should gradually carry out marketoriented reforms and obtain development funds from diversified financing channels, so as to make up for the decline in higher education funding caused by the tilt of public education expenditures to basic education. The government can guide and encourage enterprises and individuals to invest in higher education by formulating preferential policies, and in the process of cooperation between the three, enterprises can also obtain talent and technical support from universities, forming a mutually beneficial and win-win situation.

\section{REFERENCES}

[1] Becker G. S., Tomes N.. "An Equilibrium Theory of the Distribution of Income and Intergenerational Mobility” Journal of political economy, vol. 87 (6),pp. 1153-1189, June 1979. DOI: 10.2307/1833328.

[2] Lin Chen and Zhi-gang Yuan. "Better to Teach than to Give? Family Assets, Social Capital, Human Capital, and the Intergenerational Income Mobility of China". Fudan Journal (Social Science Edition), pp.99 -124. April 2012. DOI: CNKI:SUN:FDDX.0.2012-04-014.(In Chinese)

[3] Wei-tong Wang, Jia-song Xie and Ling Zhang. "Regional Intergenerational Mobility Preference of Population Migration: Micro Evidence and Influence Mechanism." Management World, pp. 89-103+135. DOI:10.19744/j.cnki.11-1235/f.2019.0094. (In Chinese)

[4] Dan A, Fredrik A. "Stratification, Social Networks in the Labour Market and Intergenerational Mobility". 
The Economic Journal, vol. 117(520), pp. 782-812. DOI: 10.1111/j.1468-0297.2007.02050.x.

[5] Hong-shu Hu and Shou-wei Qi. "The intergenerational mobility of Chinese household income distribution". Journal of Zhongnan University of Economics and Law, pp. 20-29. February 2014. DOI: 10.3969/j.issn.1003-5230.2014.02.003. (In Chinese)

[6] Bao-gui Xue, Liancheng-He. "Research on the Intergenerational Income Transmission Mechanism in China". Yunnan Social Sciences, pp.44-49. February
2016. DOI: CNKI:SUN: YSHX.0.2016-02-009. (In Chinese)

[7] Xing Zhou, Fang Wang. "Comparative study on intergenerational income flow of urban and rural households" . Journal of population, vol. 36 (02),pp. 6473,2014.DOI: 10.3969/j.issn.1004-129X.2014.02.007. (In Chinese) 